\title{
Enhanced and Changing Roles of School Librarians under the Digital Age
}

Keywords: School librarianship, Educational roles, Information literacy skills, Librarian-teacher collaboration, qualitative research

\begin{abstract}
Purpose: The current trend of fast-evolving information and communication technologies (ICT) and the emphasis on enquiry-based learning has increasing impacts on school curriculum and the required library support. We explore the recent viewpoint of classroom teachers and school administration about the role of the school librarians, which is lacking adequate studies.

Methodology: This paper is based on a qualitative analysis of interviews on three practicing secondary school librarians in Hong Kong on three separate occasions to explore a different, richer type of data, in particular new requirements and issues from which a questionnaire survey could provide.
\end{abstract}

Findings: The new roles of the school librarians improving teaching and learning effectiveness under this environment include: being information literacy specialists, leading library improvement projects, and providing classroom teaching collaboration and support.

Originality/value: This is one of very few qualitative studies reporting the professional practices and changing roles amongst school librarians in Hong Kong. Results of this study are of practical interest to education policymakers, school administrators, practicing school librarians and educators with a vested interest capitalizing on the school library's potentials to positively affect students' achievements. 


\section{Introduction}

In our earlier work (Lo et al., 2014b), we confirm from our survey that school librarians are not only managers of school libraries, but are also playing other roles such as educators, administrators, teaching consultants, information specialists and information literacy teachers. Unfortunately, in many countries, especially in Asia, there has always been a lack of understanding of such extra roles of school librarians in the public education system (Nakamura, 2000; Cheng, 2012). To make matters worse, many novice school librarians do not have a clear understanding of the potential contributions of school library programmes to students' overall development process and their academic achievements (Chan, 2008), in particular with the current trend in enquiry-based learning (Lo et al., 2014b).

Further, according to the University College London CIBER Research Team (2008) in the U.K., information skills are vital for our next generation to survive in the information age, and thus should be inculcated in schools as early as practical. However, professional literature reveals that school librarians in many countries are facing similar problems related to their professional image, role and job satisfaction (Cheng, 2012; Hartzell, 2002; Miller, 2005; Nakamura, 2000; Wong, 1992; Zhan, 2012; Zhang, 2010), together with a lack of resources, time, certified programmes and training opportunities, recognitions towards school librarians' qualifications, understanding and support amongst principals and other classroom teachers (Lo et al., 2014b).

Previous studies focus mostly on school librarian's impact on students' reading abilities and academic achievements (Lonsdale, 2003; Lance \& Hofstede, 2011) instead of examining the collaboration between the classroom teachers and librarians. As such, this study was set out to answer the following research questions:

1. To explore the emerging new roles of the school librarians under the new digital era.

2. To explore the nature and scope of new changes in the practices of amongst the school librarians through the cases in Hong Kong.

3. To identify some key professional knowledge, skills, as well as characters traits needed for the school librarians to perform their new roles effectively.

4. To determine the level of job satisfaction, as well as their own view towards their new/changed roles as school librarians in the Hong Kong context.

\section{Values \& Significance of the Study}


In particular, professional practices amongst school librarians in Hong Kong have been insufficiently studied. Previous studies were limited to small numbers of empirical quantitative studies on the issue. In fact, this is one of very few qualitative studies reporting the professional practices and changing roles amongst school librarians in Hong Kong. Results of this study are of practical interest to education-policy makers, school administrators, practicing school librarians, as well as educators with a vested interest capitalizing on the school library's potentials to positively affect students' achievements. In addition, recent advancement in information and communication technologies (ICT) and the shift towards enquiry-based learning also introduce much impact to school libraries in other Asian regions, where we anticipate the sharing our discovery will also benefit them. Our findings further provide a strong basis for developing pragmatic hypothesis and designing further questionnaires in the next phase of research by us and other researchers.

\section{Literature Review}

According to UNESCO’s 1999 School Library Manifesto, the school library should: (1) provide information and ideas that are fundamental to functioning in today's information and knowledgebased society, (2) equip students with lifelong learning skills, and (3) develop the imagination and enable students to live as responsible citizens. For these reasons, the school library is expected to function far more than just as a quiet place for study and reading. Meanwhile, the school librarian is expected to serve more than a teacher overseeing the daily operations of the physical library. There is an extensive body of literature discussing the evolving new roles amongst school librarians. The changing concept in school librarianship is closely linked with students' new mode of enquiry-based learning on one side, while new technologies and the Internet environment on the other.

To achieve more effective enquiry-based learning, students first need to become proficient in information literacy (IL), so that they can actively search for information and construct knowledge (Harada \& Yoshina, 2004 ; Kuhlthau, Maniotes, \& Caspari, 2007 ; Hepworth \& Walton, 2009). Rogers (1994) even more directly links IL with learning and libraries by defining IL as a compound of library, study, cognitive skills and additional skills necessary for independent learning. Asselin (2005) states that due to the growing number of printed and digital resources available and the expectation that student learning outcomes reflect the use of information to acquire knowledge, school librarians should take a more proactive role in helping teachers in the selection and strategic use of disparate resources in teaching. Plus, school librarians could make unique contributions in preparing students to take part in the global networked environment via IL programmes carried out 
in schools. Asselin even sees teacher-librarians as leaders in the new learning environment where information and communication technology (ICT) skills are necessary for independent learning and solving problems under the fast-evolving Internet environment.

Although Kuhlthau (1995) predicted that there would be an increased integration of information skills in the curriculum, Lupton (1995) opined that ICT might be a big challenge to school librarians, because ICT has expanded and evolved so much that many school librarians would not be able tackle fully. Several years later, Miller (2004, p. 7) concluded in her literature review that the role of school librarians is constantly changing, partly under the influence of developments in ICT. School librarians are also aware of their new roles as teachers and that this role should be performed in collaboration with other classroom teachers in order to incorporate IL skills instruction effectively into the curriculum.

As for practice, Cheng (2012) examined how teachers, students and school administrators perceive the roles and functions of the school librarians in local schools of Hong Kong. Cheng's study showed that participants still connect school librarians and school library services primarily with printed books and reading, but very rarely perceive them in contemporary roles such as information providers, IL teachers and curriculum facilitators. Often, school librarians' roles and services cannot be easily seen as contributing to students' overall learning. Leung (2007) conducted an action research on implementing IL in collaboration with a school vice-principal, a primary one General Studies teacher and the school librarian at a primary school in Hong Kong. The study concluded that positive feedbacks from the students could encourage the teaching team to try more topics with the same class. Chu (2009), in his action research, examined the benefits of enquiry-based learning in primary schools, where the teaching of IL was one of the major teaching components. The study found that the two key success factors are (i) the support of the school principal, and (ii) the collaboration between subject teachers and the school librarian.

All these studies carried out in Hong Kong conclude that school librarians are in a position to provide a valuable input to teaching and learning, but support from both the school administration and subject teachers are definitely needed to the effective realization of these potentials. Other studies also provide similar findings and conclusions in the East Asian region, such as:

- $\quad$ The survey of Nakamura (2000) to compare teachers' perceptions towards school libraries in Ohta-ku, Tokyo and Honolulu, Hawaii.

- Kasai’s (2006) exploration of the practices amongst school librarians in Japan 
- The investigation of Yang and Chen (2007) in the roles and positions of school librarians in Taiwan

- Han's (2006) study about school library developments in Korea after the Korean Government's initiatives for enhancing the developments of the school library system, by implementing a 5year master plan (2003-2007) to modernize school libraries by hiring professional librarians to work in school libraries

In summary, there have been bits and pieces of findings around the East Asia region, but these studies could not provide a holistic view about the enhanced and changing roles of school librarians under the current digital age.

\section{Research Methods}

This paper is based on a qualitative analysis of the interviews with three practicing secondary school librarians in Hong Kong on three separate occasions, namely Gloria Chan at PAOC Ka Chi Secondary School (KCSS) ${ }^{1}$, Jun Niu at the PLK Choi Kai Yau School (KKY) ${ }^{2}$ and another seasoned school librarian at a government-subsidized local secondary school, who wished to remain anonymous for this research. For the reason of confidentiality, we named the second participating school as SP.

This study was intended to be exploratory and to reveal a different, richer type of data, in particular new requirements and issues, from which a questionnaire survey could provide. Therefore, a qualitative, ethnographic approach to data collection and analysis was important. One major strength of face-to-face interviews lies in the fact that they allow 'unexpected' responses, as well as discourses to emerge. In addition to allowing the participants to articulate the answers based on their own understandings of the interview questions, such natural and free conversational interviews also enable maximum flexibility for more open, spontaneous, and instant exchanges of ideas without any preconceived expectations on the researchers' side. More importantly, a series of follow-up questions enables the participants to clarify their answers, as well as to verify immediately their responses against the researchers' understandings. In other words, allowing different 'themes' to emerge naturally during the course of the conversations, and thus developing a mutual understanding of the concepts being examined. The goal was not always the technical explanations behind specific

\footnotetext{
${ }^{1}$ PAOC Ka Chi Secondary School - Homepage. Available at: http://www.kachi.edu.hk

${ }^{2}$ Po Leung Kuk Choi Kai Yau School - Homepage. Available at: http://cky.edu.hk
} 
tasks or operations, but the immediate and direct experiences of the individuals, illustrating the underlying reasons for their actions and decisions. As Rossman \& Rallis (1997, p. 124) pointed out, the interview approach not only provides opportunities for open discussions where both the participants and researcher could "construct meaning” together, but it is also "essential for the understanding of how participants view their world.”

As the results of this study were based only on the face-to-face interviews with three practicing school librarians in Hong Kong, the collected survey results would not allow for generalization about the experiences, working conditions of other school librarians across the same region. However, this provides a strong basis for developing pragmatic hypothesis and designing further questionnaires in the next phase of research by us and other researchers.

\section{Data Analysis}

The remainder of this paper discusses particular themes emerging from the interview results. Although the questions asked in the interviews inevitably provided a rough framework for the interview results, the conversations were wide-ranging and emerging themes cut across particular questions asked at the interview. The following findings and discussions focus on themes relating to the changing roles and professional practices of the interviewees.

\subsection{School Librarians as IL Specialists}

In order to find out to what extent IL skills are being addressed at these three schools, we asked the interview participants:

"Do you agree IL skills are important components of the school library curriculum? If you agree, why do you think they are so important?"

"Do you also organize workshops and orientations for other classroom or subject teachers on a regular basis, aiming to help them familiarize with the different and new resources available at the school library, and to encourage them to integrate these library resources into their teaching?"

SP Librarian: "I have a very strong IT background. Before becoming a school librarian, I have spent over 10 years working as a software engineering in different profit and nonprofit organizations in both UK and Hong Kong. Because we know that information searching and retrieval skills could help the students to become more self-reliant, in terms of both learning, as well as problem solving. Nowadays, the Internet is such a powerful, useful and convenient tool; at the same time, students feel 
so overwhelmed with information overload! Hence, they must learn to locate, evaluate, and use the needed information found on the Internet - and this is what IL is all about. A large part of my job is to encourage students to use IT tools for different project-based work, producing reports, multimedia presentations, etc.

Gloria Chan: “[Teaching IL skills] is definitely very important and is within my job descriptions. If I have to teach IL, I would usually put more emphasis on teaching the Form 1 students (with age ranging from 12 to 14). But I do not hold classes [on IL skills] on a weekly basis. I only teach IL according to the requests issued by individual classroom teachers, or to support students to carry out their major school projects or assignments, etc."

Jun Niu: "The school that I previously worked for followed the IGCSE (International General Certificate of Secondary Education) curriculum. But, library IL skills instruction was not part of the IGCSE curriculum and is not measured under the IGCSE. However, the whole idea of information literacy (IL) is to teach students how to search for, select, evaluate, and synchronize information, and most importantly how do you apply it, etc. Of course, they are experiencing the need to introduce IL to IGCSE right now. But when I first arrived at that school, they did not believe in any of this IL instruction. So I just kept pushing IL to the school, and they [the whole school gradually] see the value and importance of IL instructions.”

According to Lo et al. (2014, p. 314), the new knowledge-based learning environment has become increasingly focused on student-centred learning and other self-taught skills. Such new learning processes are gradually replacing the traditional education system, which emphasizes on passive learning, rote memorization and spoon-feeding of knowledge with teachers as the sole providers. The interview results indicated that in these new information-rich learning environments, IL skills have become increasingly important, as well as being closely associated with the key concepts of library instruction.

\subsection{School Librarians as Classroom Teachers}

In a study carried out by Lo et al. (2014b), a large number of school librarians in Hong Kong had too many other non-library-related subject courses to teach in addition to their core library duties. In order to better understand the actual situations regarding the workload of their 'non-core' duties, as well as the inherent advantages and disadvantages associated with other non-library-related teaching, we asked the interviewees: 
"I understand many school librarians in Hong Kong also have to perform other classroom or subject teaching, in addition to their core library duties. Could you tell me what is the situation at your school? Do you think there is an advantage for the school librarians to allocate 5 to $10 \%$ of their staff time on teaching other non-library-related subject, e.g., Liberal Studies, Chinese or English languages? Or as a school librarian, you would you prefer to devote $100 \%$ of your staff time to concentrate on managing your school library?”

Gloria Chan: "In my case, I have to teach Form 4 Chinese Language. Of course it would definitely be better, if I was not needed to teach other subjects, or to take up any classroom teaching duties at all. For the reason that I could simply have more time to focus on my work that is directly related to the daily operations of the school library, as well as IL skills instructions. For example, I would like to spend more time doing book cataloguing this year, as we have acquired a lot of new books. But in reality, I need to spend time with the students - to help them prepare for several major examinations, e.g., like oral exams. In addition, I have to prepare exam papers, e.g., [for the subject of] Chinese Language, we have to prepare five different exam papers. We have to do a variety of drills, mock exams and practice tests with students - so I have to spend quite a lot of time in this regard. In addition, I am also the Chairperson of the Parent-Teacher Association, and I am also in charge of the ceremony committee, organizing big events like opening ceremony, graduation and end-of-year ceremonies, etc. If there is too much classroom teaching and too many of such 'side-duties,' it might affect my library work in the long run."

SP Librarian: "No, my teaching is all library-related or IL-related. I would very much prefer to concentrate on my core library duties. Many of my routine library tasks [e.g., cataloguing, book selections, etc.] could all take up a great deal of our [staff] time, concentration, as well as attention to deliver the [library] services with quality. For this reason, I would prefer not to get distracted by other non-library-related-teaching responsibilities..."

Jun Niu: “Generally, I don't think that librarians should take on other teaching duties as there are so much to do around the library. However, taking on other roles (teaching a subject, becoming a homeroom teacher / grade leader, or leading the yearbook or newspapers or any kind of club organization in the school) will generate a lot opportunities to bring up the visibility of the librarians in a school, especially where libraries are not used enough or librarians are not viewed as part of the faculty. Good collaboration comes from good relationship between the librarian and the teachers, and a good librarian will do anything to achieve that." 
According to Lo et al. (2014b), being able to serve as an effective curriculum facilitator has a lot to do with whether one's work is being valued or not. The interview results revealed that the 'classroom' teaching workloads amongst the practicing school librarians tended to vary between schools. If school librarians were assigned too much classroom teaching, they would easily be distracted and not be able to focus their efforts in the core library duties. In other words, the quality of library services and the associated IL skills instructions could suffer, as a result of too much classroom teaching. On the other hand, an appropriate small amount of classroom teaching would enable the school librarians to better understand the students' learning needs as well as the new changes in the curricula.

\subsection{Collaborations between School Librarians \& Classroom Teachers}

It is commonly agreed that collaborations between school librarians and subject teachers is an important facilitator that enables an effective implementation of library programmes (MontielOverall \& Hernandez, 2012). In order to identify the extent, nature and format of such collaborative relationships carried out between the school librarians and classroom teachers, we asked the 3 interview participants:

"To what extent do you collaborate with other classroom teachers, when the objectives, structure, and curricula of the secondary education in Hong Kong is extremely examoriented?”

SP Librarian: "I liaise with the teachers of three different subject areas, namely: Mathematics, English and Chinese. They will try to arrange for library lesson time. There are two classes catered for Form 4 students, and I teach them specific independent learning and also [online information] searching skills; and I share these teaching duties with other English teachers, and the course is entitled, ILT (Independent Learning \& Teaching).”

Gloria Chan: “... In terms of collaborations with other teachers, I arranged for all Form 1 to Form 5 students to visit a mega bookstore in Hong Kong - to select books for the school library. Many other subject teachers also took part in planning and organizing this event. Before this visit actually took place, I had to organize in-house training for the other teachers - teaching them how to avoid purchasing duplicate titles. The whole event was proven to be very successful and was fun, enjoyable and well-received amongst our and students." 
Gloria Chan: "For [the subject of] Liberal Studies, students are required to do extensive readings on their own. In this context, the [school] library and the [school] librarian are playing an increasingly important role in the whole school community. In my case, I make an effort to let the school community know that I am always ready to help the other teachers with their subject/classroom teaching. This year, I have worked with different subject panels, and created subject-reading lists tailor-made for their teaching. The different subjects covered by the reading lists include: Chinese, English, Liberal Studies, Mathematics, Sports, Visual Arts, Humanities, History, Geography, etc. Other science subjects, such as Information Technology and Natural Sciences were also included on these reading lists. These reading lists were tailor-made mainly for the Form 1 to 3 students. In addition, I am also teaching reading strategies to the junior students, with the aim of inspiring them to become avid readers, i.e., teaching the students how to assess the plot and enjoy the story line..."

In addition to being a specialist in IL teaching, school librarians also play a key role in collaborating in instructional design, i.e., linking curriculum, learning process, skills and resources, etc. Modeling and developing information strategies and tailor-made educational packages to improve students' overall learning outcomes is another crucial role that is expected of them, in the effective functioning of the library in the school community as a whole. In short, good school library programmes help students learn, and help teachers teach. The most successful school librarians are most likely those who collaborate with other classroom teachers as full partners in the instructional process.

\subsection{School Culture \& Principals’ Attitudes}

According to Church (2010), Hartzell (2002), Haycock (1995; 2004), Miller (1995), Shannon (2009), McGregor (2003) and Yang \& Chen (2007), the attitudes of the principals are some of the key factors influencing the effectiveness of library services in schools. On the other hand, school librarians are not considered subject leaders in the traditional sense, as they do not need to prepare students for any major or public examinations. On the contrary, the contribution of other PE or music teachers could be easily reflected in the numbers of awards or prizes won by their students. For this reason, a large number of school librarians are suffering from a lack of recognitions, as well as a lack of support from the classroom teachers and the senior management such as the principals (Lo et al., 2014b). With the aim of identifying the crucial factors for gaining support, as well as recognitions from both the principals and their peers, we asked the participants:

"Does your principal see the school library as an important resource for educational activities? More importantly, what are the critical success factors for gaining support from 


\section{the school's senior management?"}

Jun Niu: "As a school librarian, you have to understand that different schools have different cultures, as well as different management structures and styles. As a librarian, you are spending money for the school, i.e., you are dealing with money. So, the senior management would have an obligation to check on you [the librarian] more often, ensuring what you are doing for the school library is actually making sense. It is understandable because managing a budget is a very sensitive matter, especially for most education institutions. More importantly, you [the librarian] also have to understand the whole curriculum, the needs of the other teachers and what they are doing as well, etc., i.e., a much wider overview of the whole school community, in order to have a much bigger, and a very influential role to play. Supporting the information and reading needs of the students is just a very small part of our many duties. Hence, we librarians have to know everything that is going on within the whole school."

Jun Niu: "There is no doubt that most schools would have much lower number of senior teachers. Maybe only 10 out of 200 teachers could eventually get promoted and become senior teachers or subject leaders. Hence, the opportunities for promotion are indeed very limited as well as competitive; and will only be awarded to the individuals who could bring the most to the whole school community. For this reason, many school librarians in Hong Kong are frustrated about their narrow and unpromising career paths, causing them to feel they are not important within their school. Although they have all the required qualifications [teacher diploma, school librarian certificates, etc.], they are being not well recognized. For this reason, some of these school librarians are the burnout teachers - they don't enjoy teaching anymore; they can't or don't want to face the students anymore; and they don't want to deal with the parents anymore. A combination of all these different factors leads them to take up the 'easy' job as a school librarian. But the job of a school librarian is definitely NOT easy if you take it seriously - it is not easy at all!”

Gloria Chan: "Our principal is very supportive and open-minded. When we first started redesigning and re-modeling our school library, I asked him how he wished the new library to be. His answer was very simple. He just wished the library to be more Starbucks-like, i.e., popular social place amongst the students, where they could spend time there to enjoy the space, regardless they are going there to read or just to hang out with friends." 
SP Librarian: “I don't have statistics to support my speculations. So I can only guess - I think it really depends on the school type. Our school is half-subsidized by the local Government, and halfsubsidized by our church. And then of course it depends on the school culture as well, i.e., see how serious does the principal regard the school librarian as an important position within the whole school - how serious does he/she view voluntary reading and self/independent learning as part of students' education. Based on the resources and supports I received and the amount of responsibilities I have to undertake, I am sure our principal takes me [the librarian position] very seriously. I do welcome this decision, because that gives me a lot of time, resources and freedom to fully exercise my professional knowledge and skills to the best advantage for the overall success and welfare of the whole school."

Gloria Chan: "Whether the principal values the library depends entirely on how well you do your job. In return, I always make an effort to let him know what activities and classes are being held at the library. I constantly remind the principal and other teachers that the school library is the heart and soul of the whole school, as well as converting our library into a showcase for our visitors."

All three interviewees took part in this study are very seasoned professionals, and each excels in their own ways. The interview results indicated that advocating of creating relationships on all levels is the best way to gain support for the school librarians' endeavours. Understanding the school culture is also a crucial step for the school librarians to create opportunities for effective collaboration with other classroom teachers. An effective way to gain recognitions and lasting success is to take up a proactive role in providing other classroom teachers with the support and resources to meet the curriculum needs, as well as to develop the support needed to create a literate environment for fostering the students to become information-literates.

\subsection{Library Improvement Projects and Opportunities}

The lack region-wide syllabus and school library standards has enabled a great deal of flexibility for the individual school librarians to bring in their own distinctive professional knowledge and skills, which may contribute to the design of effective school library programmes. In order to find how they managed to turn this challenge into an advantage, we asked:

"Were there situations where you could apply their previous professional skills and experiences in implementing any major library projects?” 
Jun Niu: "Coming from a public librarianship background, the concepts of servicing the general public are found to be most useful. Originally, the magazines [at our school library] could not be loaned out by the students and I immediately commented, “Why not?!” In addition, I did not understand why the students were not even allowed to check out the back issues either, then I was told that because the back issues were not catalogued, as they had no barcodes attached. So we decided to change all that; and two months later, we completed cataloguing the entire magazine collection. And now, not only you could search these magazine titles via OPAC, and you could also check them out of the library. So I would say most students prefer a more user-friendly library policy. In other words, making the policy more flexible, so that the library materials would become more accessible to them, and making their library experiences more enjoyable in return."

Gloria Chan: "Not long ago, our library underwent a major extension and renovation. In addition to negotiating with the architect and the contractor, I also took the initiatives of approaching different well-known corporations in Hong Kong to ask for [financial] donations. Luckily, I was able to raise 40 million [Hong Kong] dollars ${ }^{3}$ for this library extension project. There was so much extra [administrative] work involved. But being able to see our students enjoy spending time in the library, all the extra hard work turned out to be worthwhile.... In addition, I have a friend who works for a comic book store, so I suggested him giving out some free comics to our school. I think if students are willing to spend more time on reading, I don't mind spending time on too, because I do hope they can come to the library. I will do what all I can do. Actually I only hope they like reading books, just as simple as this.”

SP Librarian: “Major project in 2014 would include refurnishing the school library with new desks, reading chairs, new pictures and thereby creating a new and more attractive atmosphere. In addition, the training of new teachers is in fact an important part of my duty as a school librarian, i.e., to provide training to all new teachers at the beginning of each academic year. And teaching them the skills on how to use the online databases...”

As the SP Librarian spent many years working in the professional IT field before entering a career in school librarianship, she focuses on using IT-related to teachers. Gloria Chan excels in public relations, and she succeeded in raising a large sum of money from many external donors for rebuilding her library. Finally, Jun Niu has a strong public librarianship background, and she made

\footnotetext{
${ }^{3} 1$ US\$ $=7.8 \mathrm{HK} \$$ as pegged by the Hong Kong Government since 1983.
} 
major changes in both cataloguing and circulation policies to create a better library experiences for the students. In summary, these librarians have made good use of their previous experience and knowledge to improve their libraries.

\subsection{Major Challenges Faced by School Librarians}

At the same time, the lack region-wide syllabus and school library standards could also provide a lot of challenges to school librarians, especially for inexperienced ones. For example, despite of its importance, students are not subject to any standardized public examinations devoted to library or IL skills. To explore the opposite side of the coin, we asked the participants:

"Since there is no region-wide syllabus to follow, do you think this makes the job of a school librarian much more difficult, in comparison to the work of other Mathematics, History or English teachers?”

Gloria Chan: "The school librarian is often considered the 'loneliest' position within the whole school. Unlike other subject teachers, e.g., Chinese, English or Mathematics teachers, there is usually a team of teachers under the subject leader. In other words, there is always someone with whom you could consult about your work. However, it is not always the case for the school librarian, as he or she is doing 'solo' work most of the time. However, it really depends on whether you are willing to take one step further to cooperate with other teachers. Another major challenge is that for library lessons, there is no checklist-like regional-wide syllabus to follow. So if you are inexperienced and new to the field, and you do not have someone to guide you, you could easily feel frustrated or lost."

Jun Niu: "Absolutely! But I think these all depend on how much you yourself want to do as a school librarian. At the end, it all comes down to our own professional judgments, our experiences, and whether we see the need to give library lessons at this particular time, and how frequently these lessons should be given....”

Indeed, not having to follow a regional-wide syllabus or school library standards could also serve as a double-edged sword. Good professional practices and competencies come with experiences. Experiences come with age, persistent practice, continuous learning, as well as life lessons. Successful partnerships between school librarian and other subject teachers also take many years to develop. It also takes a great deal of effort to maintain this partnership under an ongoing basis. At their current workplace, all three librarians are given a great deal of freedom to exercise their 
professional knowledge and expertise to the fullest. On the other hand, inexperienced or entry-level librarians could find such "freedom" and "flexibility" difficult to cope and easily leading to confusion and frustration.

\section{Discussion and Conclusion}

This study has offered practical advices and examples for becoming a successful school librarian in the Hong Kong education context. In short, all three school librarians took part in this study were expected to serve as a 'natural bridge' for interdisciplinary instructions across the whole school community. The results from this study are supportive to the findings of (Lo et al., 2014b; Church, 2010; Hartzell, 2002, Haycock, 1995; Miller, 2005; Shannon, 2009).

This study provides evidence of the positive impacts of school librarians with their multi-faceted contribution such as competent administrators, teaching partners, ICT consultants, teachers, in particular their role as IL specialists. The interview results further confirmed that the school library is an essential part of the local school education system in Hong Kong, despite the system is heavily exam-oriented. Findings also indicated that with the increasing emphasis of the enquiry-based learning, many areas of the school curriculum are dependent more and more on both services and resources provided by the school library for the ongoing support of teaching, learning as well as recreation of students at all levels.

The rapid change in ICT requires school librarians to be equipped a variety of professional knowledge and IL skills in particular. The interview results also indicated a vital importance of IL skills for enabling students to access, evaluate, interpret, and apply information from both printed and non-printed resources. For this reason, school librarians are also expected to be proactive in seeking out and incorporating resources in a variety of formats into their work, with the aim to support and enhance students' learning experiences, as well as their motivation towards voluntary reading. All three interviewees demonstrated high level of self-confidence, as well as competencies in using ICT as a medium for IL skills instructions, as well as improving their school libraries towards the rapidly-evolving global ICT environment.

Owing to their distinctively different educational and professional backgrounds, despite carrying the same job title, the scope of practice and their specialties vary greatly among the three librarians being 
interviewed. Unlike other subject teachers, there is no 'checklist-like' regional-wide syllabus or school library standards, which the school librarians can just observe and follow. This provides both opportunities and challenges, but these three school librarians have taken the better side of opportunities in the freedom to exercise their professional knowledge and skills by exploring a variety of independent or collaborative teaching approaches, leading to a wide variation in libraryoriented programmes. Such library programmes help students and teachers become active and efficient users of information; students to become independent learners and keen voluntary readers. Factors leading to the effective library programmes carried out by these three interviewees are summarized as follows:

1. The school librarian is often a 'solo' position, and he/she is expected to work independently most of the time. For this reason, being able to understand the school culture and its management climate is considered highly important. Understanding the school culture also means being aware of the different resources and options available. Such an understanding would facilitate one to work within or around the school culture - so that library programmes developed will be in line with the school's philosophy and practice.

2. To be able to effectively developing various strategies to extend the classroom curriculum and recreational reading through close educational partnerships with other subject teachers, school librarians require the necessary confidence and promotional skills similar to that of a marketing manager: being self-motivated and not afraid to take up extra work, and being innovative and able to constantly thinking outside the box.

3. Teamwork is essential. Different subject teachers may have different working styles and needs; hence, one needs to be able to work collaboratively with other teachers across varying disciplines. For this matter, it is crucial that school librarians remain flexible, adaptive, creative, innovative, as well as up-to-date (i.e., being aware of the new changes across the whole curriculum).

4. Finally, school librarians must also possess a dedication and strong belief that what they do as school librarians could have major and positive impacts on students’ overall learning.

5. Having a supportive principal plays a key role in fostering successful library programmes, as well as fruitful librarian-teacher collaborations. In return, school librarians as active 
participants in the curriculum are vital for earning supports and recognitions from both the principals and other classroom teachers.

For our continuing research, we are developing hypothesis and designing questionnaires in our next phase of research, in which we plan to investigate the issues quantitatively in Hong Kong, China, Taiwan, and Japan.

\section{References}

Asselin, M. (2005). "Redefining the school libraries’ role in literacy teaching and learning.” In R. Doiron and M. Asselin (eds.) Literacy, libraries and learning: Using books and online resources to promote reading, writing and research. Toronto, ON: Pembroke Publishers, pp. 9-18.

Chan, C. (2008). "The impact of school library services on student achievement and the implications for advocacy.” Access, 22(4), pp. 15-20.

Cheng, Po-ying. (2012). Perceiving usefulness: The perception of users on school libraries and librarians in Hong Kong. Doctoral dissertation, Charles Sturt University, Wagga Wagga, Australia. Available at: http://researchoutput.csu.edu.au/R/?func=dbin-jumpfull\&object_id=35229\&local_base=GEN01-CSU01

Chu, S. (2009). "Inquiry Project-Based Learning with a Partnership of Three Types of Teachers and the School Librarian.” Journal of the American Society for Information Science and Technology, 60(8), pp. 1671-1686.

Church, A.P. (2010). "Secondary school principals' perceptions of the school librarian's instructional role.” School Library Research, 13, pp. 1-33.

Han, Yoon-ok. (2006). “Korea: a study of school library development.” School Libraries Worldwide, 12(1), pp. 70-80.

Harada, V.H., \& J.M. Yoshina. (2004). Inquiry Learning Through Librarian-Teacher Partnerships. Worthington, Ohio: Linworth Publishing.

Hartzell, G. (2002). “The principal’s perceptions of school libraries and teacher librarians.” School Libraries Worldwide, 8(1), pp. 92-110.

Haycock, K. (1995). "Research in teacher-librarianship and the institutionalization of change." School Library Media Quarterly, 23(4), pp. 227-233.

Haycock, K. (2004). “Research about collaboration.” Teacher Librarian, 31(3), pp. 48.

Hepworth, M.E. \& G.L. Walton. (2009). Teaching Information Literacy for Inquiry-Based Learning. Oxford: Chandos Publishing.

Herring, J. \& A.M. Tarter. (2007). "Progress in developing information literacy in a secondary school using the PLUS model.” School Libraries in View, 23, pp. 3-7. 
IFLA/UNESCO School Library Manifesto $1999 . \quad$ Available at: http://www.ifla.org/publications/iflaunesco-school-library-manifesto-1999

Kasai, Y. (2006). "School Library Challenge in Japan-LIPER-SL: Library and information Professions and Education Renewal, School Library Research Group Report.” In C. Khoo, D. Singh \& A.S. Chaudhry. (eds.) Proceedings of the Asia-Pacific Conference on Library \& Information Education \& Practice 2006, (pp. 436-444). Singapore: School of Communication \& Information, Nanyang Technological University.

Kuhlthau, C. C. (1995). “The process of learning from information.” School Libraries Worldwide, 1(1), pp. 1-12,

Kuhlthau, C.C., L.K. Maniotes, \& A.K. Caspari. (2007). Guided Inquiry: Learning in the $21^{\text {st }}$ Century. Portsmouth, NH: Libraries Limited.

Lance, K. C., \& L. Hofstede. (2011). "Something to shout about: New research shows that more librarians means higher reading scores.” School Library Journal, 57, pp. 28-33.

Leung, Y.H.A. (2007). "Cooperative Planning and Teaching (CPT) between Teachers and the Teacher Librarian in a Hong Kong Primary School to Equip Students with Information Literacy Skills.” IASL Conference 2007. Taipei, Taiwan.

Lo, Patrick, Joyce Chen, Zvjezdana Dukic, You-ra Youn, Yuji Hirakue, Masaaki Nakashima \& Guanghui Yang. (2014). "The roles of the school librarians as information literacy specialists: a comparative study between Hong Kong, Shanghai, South Korea, Taipei and Japan.” New Library World, 115(7/8), pp. 314-338.

Lo, Patrick, Dana Dukic, Joyce Chen, You-ra Youn, Yuji Hirakue, Masaaki Nakashima \& Guanghui Yang. (January, 2014b). "Attitudes and self-perceptions of school librarians in relations to their professional practices: a comparative study between Hong Kong, Shanghai, South Korea, Taipei and Japan.” School Libraries Worldwide, 20 (1), pp. 51-69.

Lonsdale, M. (2003). Impact of School Libraries on Student Achievement: A Review of the Research. Victoria: Australian Council for Educational Research.

Lupton, P. (1995). "Facilitating the Integration of Information Technology into the Primary Curriculum: Part of the Teacher-Librarian's Role?” Sustaining the Version. Selected papers from the Annual Conference of the International Association of School Librarianship. Worcester, England.

McGregor, Joy H. (2003). “Collaboration and Leadership.” In Curriculum Connections through the Library. Barbara K. Stripling \& Sandra Hughes-Hassell (Eds.) Westport, CT: Libraries Unlimited, pp. 119-219.

Miller, K. (2005). "Novice teachers' perceptions of the role of the teacher-librarian in information literacy.” School Libraries in Canada, 24(3), pp. 8-26.

Montiel-Overall, P. (2008). "Teacher and librarian collaboration: a qualitative study.” Library \& Information Science Research, 30, pp. 145-155. 
Montiel-Overall, Patricia \& Anthony C.R. Hernandez. (2012). "The effect of professional development on teacher and librarian collaboration: preliminary findings using a revised instrument, TLC-III.” School Library Research, $15 . \quad$ Available at: http://www.ala.org/aasl/sites/ala.org.aasl/files/content/aaslpubsandjournals/slr/vol15/SLR_EffectofP DonCollaboration_V15.pdf

Nakamura, Y. (2000). “Teachers' perceptions of school librarians: Comparisons from Tokyo and Honolulu.” School Libraries Worldwide, 6(1), pp. 66-82.

PAOC Ka Chi Secondary School - Homepage. Available at: http://www.kachi.edu.hk

Po Leung Kuk Choi Kai Yau School - Homepage. Available at: http://cky.edu.hk

Pollard, D. (2005). “How we can improve collaboration.” Available at: http://blogs.salon.com/0002007/2004/11/22.html\#a961

Rogers, Rick. (1994) Teaching Information Skills: a Review of the Research and Its Impact on Education. London: Bowker-Saur.

Rossman, G.B. \& S.F. Rallis. (1998). Learning in the Field: an Introduction to Qualitative Research. Thousand Oaks, Calif. Sage Publications.

Shannon, D.M. (2009). “Principals’ perspectives of school librarians.” School Libraries Worldwide, 15(2), pp. 1-22.

Wong, C. (1992). Factors Affecting the Job satisfaction of Teacher-Librarians in Aided Secondary Schools of Hong Kong. (Master's thesis). Hong Kong: University of Hong Kong.

Yang, M.H. \& Chen, K.Y. (2007). “Teaching support of Taipei senior high school libraries.” IASL Conference 2007. Taipei, Taiwan. Available at: http://nccur.lib.nccu.edu.tw/bitstream/140.119/21938/1/206_200707_Teaching+Support+of+Taipei+ Senior+High+School+Libraries.pdf

Zhan, W., Zhou, Y. \& Liu Z. (2012). "Burnout analysis of influencing factors for school librarians.” Library and Information Service, 56(19), pp. 69-73, 94.

Zhang, J.J. (2010). "The status and role of children's libraries in the field of education of our children.” Science \& Technology Information, 1, pp. 1060-1061. 